\title{
Photocatalytic Degradation of Acid Yellow 36 Using Zinc Oxide Photocatalyst in Aqueous Media
}

\author{
Sajjad Khezrianjoo and Hosakere Doddarevanna Revanasiddappa \\ Department of Chemistry, University of Mysore, Manasagangotri, Mysore 570006, India \\ Correspondence should be addressed to Hosakere Doddarevanna Revanasiddappa; hdrevanasiddappa@yahoo.com
}

Received 14 September 2012; Revised 26 December 2012; Accepted 16 January 2013

Academic Editor: David W. Mazyck

Copyright (c) 2013 S. Khezrianjoo and H. D. Revanasiddappa. This is an open access article distributed under the Creative Commons Attribution License, which permits unrestricted use, distribution, and reproduction in any medium, provided the original work is properly cited.

\begin{abstract}
A detailed investigation of photocatalytic degradation of Acid Yellow 36 (AY36) has been carried out in aqueous heterogeneous medium containing $\mathrm{ZnO}$ as photocatalyst in a batch reactor. The effects of some parameters such as $\mathrm{pH}$, catalyst loading, and ethanol concentration were examined. Solutions with initial concentration of $50 \mathrm{mg} \mathrm{L}^{-1}$ of dye, within the range of typical concentration in textile wastewaters, were treated at natural $\mathrm{pH}$ of 6.93 and catalyst concentration of $1 \mathrm{~g} \mathrm{~L}^{-1}$ after 180 min irradiation. Investigations on the active species indicated that hydroxyl radicals play the major role in the process. Experiments showed that the most efficient $\mathrm{pH}$ on the removal of the dye with photocatalytic degradation process was 8 ; however, acidic $\mathrm{pH}$ was favored for the dark surface adsorption. Electrical energy consumption per order of magnitude for photocatalytic degradation of AY36 has been also determined.
\end{abstract}

\section{Introduction}

Textile processing industries nowadays are widespread sectors in developing countries. Among the various processes in the textile industry, dyeing process uses large volume of water for dyeing, fixing, and washing processes. The textile industry uses about 10000 different dyes and the worldwide annual production of dyestuffs is over $7 \times 10^{5}$ tons [1]. Among several classes of textile dyestuffs, the reactive dyes contribute about $50 \%$ [2] of the total market share and the most common group used as chromophore is the azo (70\%), followed by anthraquinone [3]. It has been documented that dye loss in wastewaters could vary up to $50 \%$ during manufacturing or processing operations [2]. The release of those colored wastewaters in the ecosystem constitutes a dramatic source of pollution which causes these effluents to be toxic and mostly nonbiodegradable. Namely, the coloration is visible even in a very low dye concentration (below $1 \mathrm{mg} \mathrm{L}^{-1}$ ) [4, 5]. Consequently, technological systems for the removal of organic pollutants such as adsorption on active carbon, reverse osmosis, ion exchange on synthetic adsorbent resins, ozonation, and biological methods were examined [6]. All of them have advantages and drawbacks but these processes have very high operating costs. However, these conventional treatment methods cannot effectively remove the dyes from effluents, so finding an effective technique is necessary [6].

Recently, an increasing attention has been devoted to developing dye treatment methods from waste stream at its source (ISO 14001, October 1996). An alternative to conventional methods, "advanced oxidation processes" (AOPs) have been developed based on the generation of very reactive species such as hydroxyl radicals. The generated hydroxyl radicals can oxidize a broad range of organic pollutants quickly and non-selectively [7, 8]. Among the (AOPs), heterogeneous photocatalysis appears as an emerging solution to the environmental pollution of aquatic system. This process consists of the nonselective destruction of organic compounds in presence of UV light and photocatalysis systems such as $\mathrm{TiO}_{2}, \mathrm{ZnO}$, and $\mathrm{CdS}[8] . \mathrm{TiO}_{2}$ has been the dominant semiconductor photocatalyst; the domination of this catalyst can be attributed to its superior photocatalytic oxidation ability and nonphoto-corrosive and nontoxic characteristics [7]. 


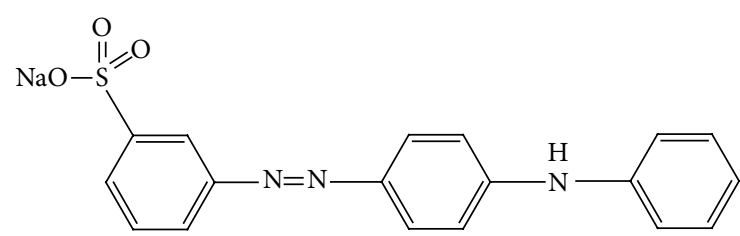

Figure 1: Chemical structure of Acid Yellow 36 (AY36).

However, the widespread use of $\mathrm{TiO}_{2}$ and platinum catalyst is uneconomic for large-scale water treatment operations. $\mathrm{ZnO}$ appears to be a suitable alternative to $\mathrm{TiO}_{2}$ since its photodegradation mechanism has been proven to be similar to that of $\mathrm{TiO}_{2}$ [9]. $\mathrm{ZnO}$ has been reported, sometimes, to be more efficient than $\mathrm{TiO}_{2}$; its efficiency has been reported to be particularly noticeable in the advanced oxidation of pulp mill bleaching wastewater [10], the photooxidation of 2-phenylphenol [11], and photocatalytic degradation of Acid Violet 7 [12]. The biggest advantage of $\mathrm{ZnO}$ in comparison with $\mathrm{TiO}_{2}$ is that it adsorbs over a larger fraction of UV spectrum and the corresponding threshold of $\mathrm{ZnO}$ is $425 \mathrm{~nm}$ [13].

AY36 is a water soluble substantive dye and has a vast amount of applications in several industries [2]. Several photocatalytic degradation methods have been attempted to the treatment of this azo dye. Titanium dioxide (Degussa P25) [2] and photocatalytic membrane reactors (PMRs) [14] have been used to remove the AY36; meanwhile, degradation of this azo dye with methylene blue immobilized resin Dowex 11 photocatalyst was carried out by Pratibha and Meena [15]. The aim of the present work is to investigate the influence of various parameters on photocatalytic degradation of a monoazo dye, "Acid Yellow 36," in the presence of $\mathrm{ZnO}$ particles, and irradiated by the UV light in a suspended and circulated reactor.

\section{Experimental}

2.1. Reagents and Photocatalytic Reactor. All reagents were used as received without further purification. The Acid Yellow 36 dye $\mathrm{C}_{18} \mathrm{H}_{14} \mathrm{~N}_{3} \mathrm{NaO}_{3} \mathrm{~S}$ (CI No. 13065, CAS No. 587-98-4, $\mathrm{MW}=375.38$ ) was provided from S.D Fine Chem., India, with purity of $98 \%$. The molecular structure of this dye is shown in Figure 1. ZnO catalyst was obtained from Lobal Chemie, India, the crystal structure of this material was zinc blende; with particle size of $1-5 \mu \mathrm{m}$ and purity of $99 \%$. Hydrochloridric acid, sodium hydroxide, and ethanol were of laboratory reagent grade (Merck products). Distilled water was used to prepare the solutions and the experiments were done in ambient temperature.

For the degradation process a circulating photoreactor made of glass with a cube body shape $(27 \mathrm{~cm}$ length, $20 \mathrm{~cm}$ width, and $4 \mathrm{~cm}$ height) was used. The 18 watt low-pressure mercury UV lamp (Philips TUV PL-L) was positioned on top of the reactor with $15 \mathrm{~cm}$ distance from the surface of solution. The liquid film in the reactor was $19 \mathrm{~mm}$ thick. The photocatalytic reactor system was operated in a batch mode and after each experiment the reactor solution was disposed. A pump was circulating the solution from on corner to the opposite corner; in this way, both the well mixing and fluidizing of catalyst particles were provided. The whole reactor body was covered with reflectors of polished aluminum thin layer. Since the photocatalysis is sustained by a ready supply of dissolved oxygen, air was supplied to the four corners of the reactor at constant flow rate using a microair compressor.

2.2. Photocatalytic Experimental Procedure. To perform the experiments, one liter of solution containing $50 \mathrm{mg} \mathrm{L}^{-1}$ of AY36 $\left(1.33 \times 10^{-4} \mathrm{M}\right)$, which is within the range of typical concentration in textile wastewaters [16] and a known amount of $\mathrm{ZnO}$ concentration, was prepared. The $\mathrm{pH}$ was adjusted to the desired value by using a pH meter (Elico LI 127). The experiments were carried out in room temperature. To start the degradation, the solution was transferred to the reactor, and the lamp was switched on. During each experiment, circulation of suspension was maintained to keep suspension homogenous. Samples $(5 \mathrm{~mL})$ were taken at regular time intervals and then centrifuged to separate the $\mathrm{ZnO}$ particles from the samples. Analyses were performed with UV-Vis spectrophotometer (Systronics 168) provided with $1 \mathrm{~cm}$ matched quartz cells. The degradation efficiency or conversion $(X)$ of AY36 with respect to its initial concentration at any time can be obtained by

$$
X=\frac{C_{\mathrm{o}}-C}{C_{\mathrm{o}}},
$$

where $C_{\mathrm{o}}$ and $C$ are its initial and concentration at a given time.

\section{Results and Discussion}

3.1. Effect of $U V$ Irradiation and $\mathrm{ZnO}$ Particles. Figure 2 demonstrates the enhancement of AY36 photodegradation in the presence of $\mathrm{ZnO}$ particles. In the presence of $\mathrm{ZnO}$, about $97 \%$ of dye degrades in an irradiation time of $180 \mathrm{~min}$; under its natural $\mathrm{pH}$ (6.93). This was contrasted with $3.1 \%$ decolorization for the same experiment performed without $\mathrm{ZnO}$ (photolysis). These experiments demonstrated that both UV light and a photocatalyst were needed for the effective destruction of AY36.

The more activity of the UV/ZnO process is due to the well-known electron promotion from the valance band to the conduction band of the semiconducting oxide to give electron-hole pairs $[17,18]$. The valance band hole $\left(\mathrm{h}_{\mathrm{VB}}^{+}\right)$ potential is positive enough to generate hydroxyl radicals at the surface; also, they can react with the adsorbed dye molecules. The conduction band electron $\left(\mathrm{e}_{\mathrm{CB}}^{-}\right)$is negative enough to reduce the oxygen molecules present in the solution. The hydroxyl radical is an extremely strong, nonselective oxidant $\left(E_{o}=+3.06 \mathrm{~V}\right)$ which leads to the partial or complete degradation of several organic chemicals. The simplified notional mechanism of photocatalytic degradation 


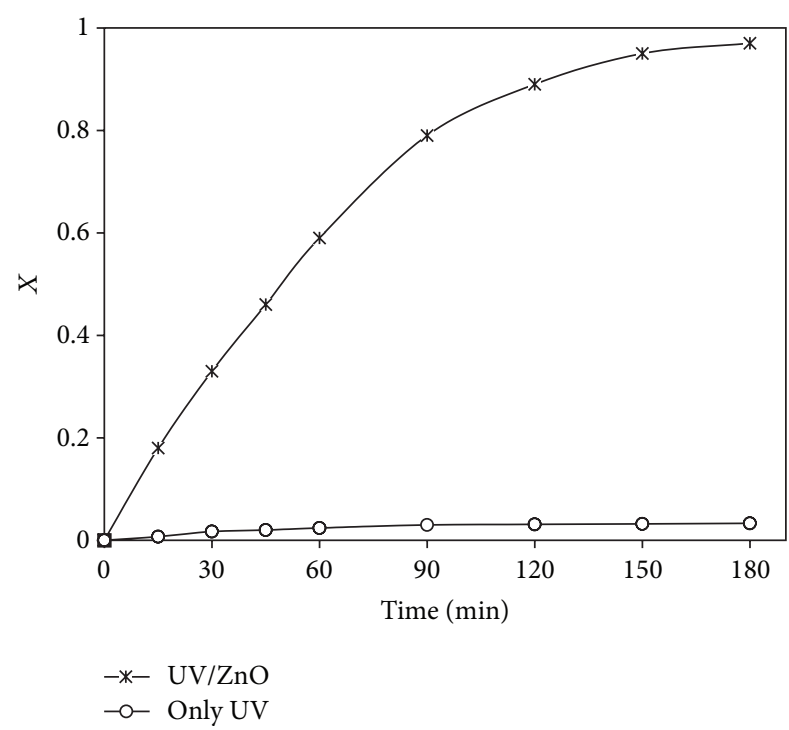

FIGURE 2: Effect of UV light and $\mathrm{ZnO}$ particles on removal of AY36, $[\mathrm{AY} 36]_{\mathrm{o}}=50 \mathrm{mg} \mathrm{L}^{-1},[\mathrm{ZnO}]=1 \mathrm{~g} \mathrm{~L}^{-1}$, and $\mathrm{pH}=6.93$.

of pollutions white zinc oxide photocatalyst is described as follows [17, 18]:

$$
\begin{gathered}
\mathrm{ZnO}+h v \longrightarrow \mathrm{ZnO}\left(\mathrm{e}_{\mathrm{CB}}^{-}+\mathrm{h}_{\mathrm{VB}}^{+}\right) \\
\mathrm{h}_{\mathrm{VB}}^{+}+\mathrm{Sub}_{(\mathrm{ads})} \longrightarrow \mathrm{R}^{\cdot}+\mathrm{H}_{2} \mathrm{O} \\
\mathrm{h}_{\mathrm{VB}}^{+}+\mathrm{H}_{2} \mathrm{O}_{(\mathrm{ads})} \longrightarrow \mathrm{H}^{+}+{ }^{\circ} \mathrm{OH}_{(\mathrm{ads})} \\
\mathrm{h}_{\mathrm{VB}}^{+}+\mathrm{OH}^{-}(\mathrm{ads}) \\
\mathrm{e}_{\mathrm{CB}}^{-}+\mathrm{OH}_{(\mathrm{ads})} \longrightarrow \mathrm{O}_{2}^{-}{ }_{(\text {ads })} \\
\mathrm{h}_{\mathrm{VB}}^{+}+\mathrm{e}_{\mathrm{CB}}^{-} \longrightarrow \text { heat (recombination) } .
\end{gathered}
$$

Subscript "ads" refers to species adsorbed on the surface of catalyst.

3.2. UV-Vis Spectra Changes. AY 36 is a monoazo dye in which the chromophore part of molecular structure contains azo linkage. Azo bond is most active in this dye and it can be decomposed by positive holes and hydroxyl radicals [19]. Figure 3 shows the changes in the optical densities at $450 \mathrm{~nm}$ and at $330 \mathrm{~nm}$ of AY36 in different irradiation times under natural $\mathrm{pH}$ of 6.93 and $\mathrm{ZnO}$ concentration of $1 \mathrm{~g} \mathrm{~L}^{-1}$. The decrease of absorption peak at $\lambda=450 \mathrm{~nm}$ relating to the $-\mathrm{N}=\mathrm{N}$ - double bond of the azo dye reveals AY36 decolorization in the presence of $\mathrm{ZnO}$ suspension after about $180 \mathrm{~min}$. However, the degradation of aromatic part of the dye molecule at $\lambda=330 \mathrm{~nm}$ takes more time.

3.3. Effect of Catalyst Concentration. For economic removal of dye effluent from wastewater, it is necessary to find the optimum amount of catalyst for efficient degradation. The influence of $\mathrm{ZnO}$ concentration on the degradation is shown in Figure 4. The photodegradation efficiency increases with the increase in the amount of photocatalyst until about $1 \mathrm{~g} \mathrm{~L}^{-1}$

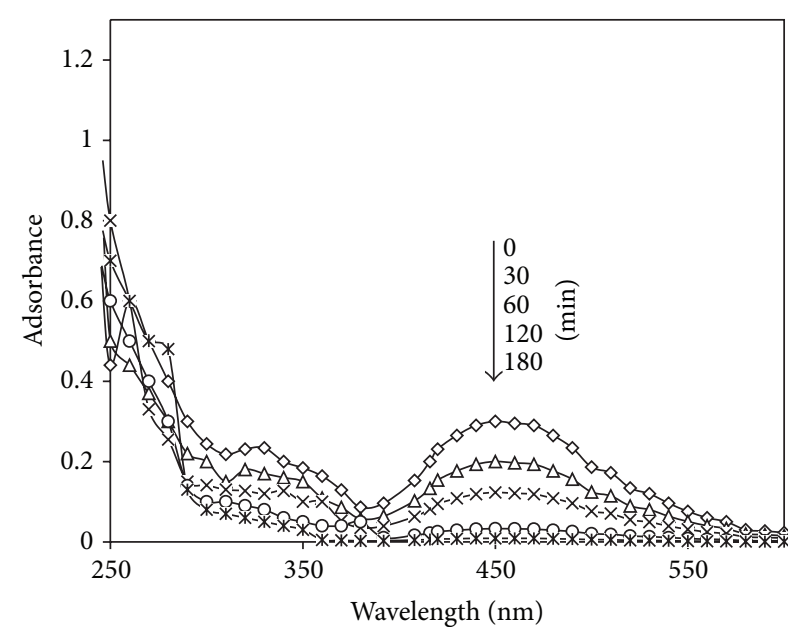

FIgURE 3: UV-Vis spectra changes of AY36 at different irradiation times $[\mathrm{AY} 36]_{\mathrm{o}}=50 \mathrm{mg} \mathrm{L}^{-1},[\mathrm{ZnO}]=1 \mathrm{~g} \mathrm{~L}^{-1}$, and $\mathrm{pH}=6.93$ (natural).

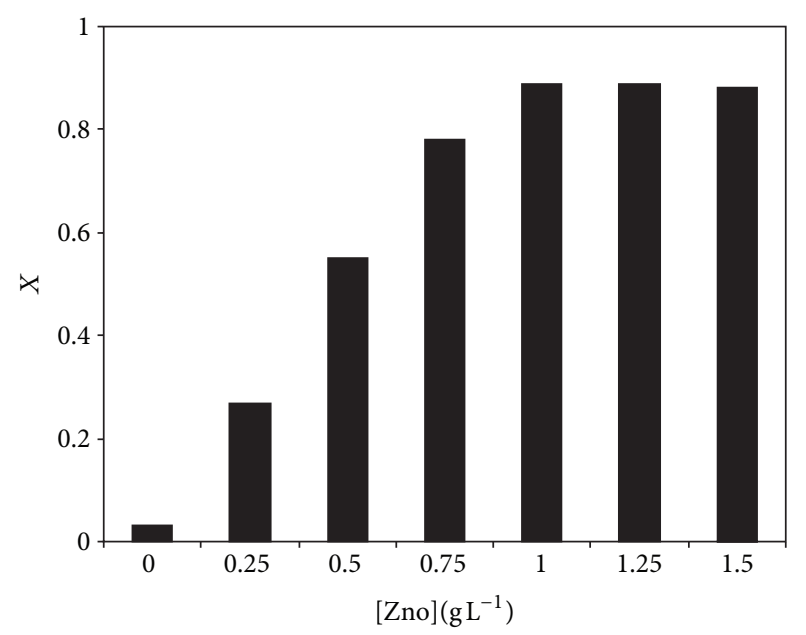

Figure 4: Effect of the amount of $\mathrm{ZnO}$ on degradation of AY36 at irradiation time of $120 \mathrm{~min},[\mathrm{AY} 36]_{\mathrm{o}}=50 \mathrm{mg} \mathrm{L}^{-1}$ and $\mathrm{pH}=6.93$.

and then decreases moderately. Increase in the number of $\mathrm{ZnO}$ particles increases the active site of the catalyst. This cause an enhancement in the hydroxyl radical generation; meanwhile, the greater number of the dye molecules could be adsorbed on catalyst surface. On the other hand, adding extra catalyst particles lead to an opacity enhancement which in turn would provide reductions in the light intensity throughout the solution [7].

3.4. Effect of $p H$. An important operational parameter in wastewater treatments is $\mathrm{pH}$. Figure 5 demonstrates the photocatalytic degradation of AY36 at different $\mathrm{pH}$ values. The maximum degradation (98\%) was observed at $\mathrm{pH} 8$ after 120 min of irradiation. In alkaline solutions photodegradation efficiency was more than that in acidic solutions. It can be due to more efficient formation of hydroxyl radicals in alkaline solution [4] and photodecomposition of $\mathrm{ZnO}$ in acidic solutions [11]. The dissolution mechanism of $\mathrm{ZnO}$ due 


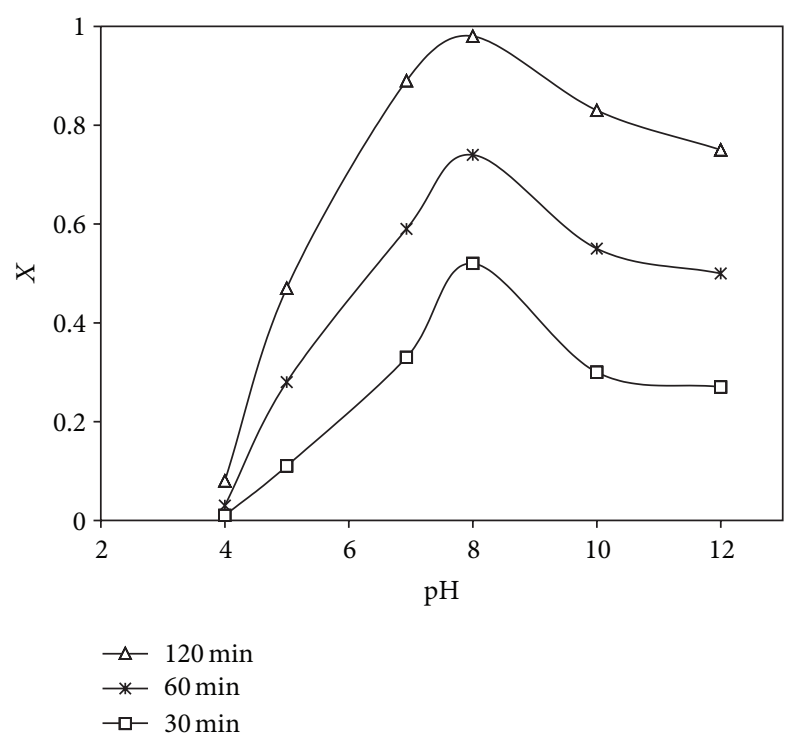

FIgURE 5: Effect of $\mathrm{pH}$ on degradation of AY36 at different irradiation times, $[\mathrm{AY} 36]_{\mathrm{o}}=50 \mathrm{mg} \mathrm{L}^{-1}$ and $[\mathrm{ZnO}]=1 \mathrm{~g} \mathrm{~L}^{-1}$.

to a classical chemical process has been demonstrated in the literature [11].

On the other hand, adsorption of AY36 molecules on the catalyst surface can affect the degradation efficiency. To study the influence of substrate adsorption on the catalyst particles surface, a series of experiments was carried out while the UV light was absent; results are presented in Figure 6. Since the zero point charge $\left(\mathrm{pH}_{\mathrm{zpc}}\right)$ of $\mathrm{ZnO}$ particles is $9.0 \pm 0.3$ [20], catalyst surface is positively charged in acidic media $(\mathrm{pH}<9)$ whereas it is negatively charged under alkaline condition $(\mathrm{pH}>9)$. Meanwhile, AY36 has a sulfuric group in its structure, which is negatively charged; therefore, dye cannot be adsorbed on photocatalyst surface effectively in the alkaline solution $(\mathrm{pH} \geq 9)$. Maximum amount of dye adsorption on the catalyst surface was observed in the $\mathrm{pH}$ of 4.

3.5. The Role of Different Active Species. It is well known that in the photocatalytic degradation process two main species have the major contributions; electrons and holes $\left(\mathrm{h}_{\mathrm{VB}}^{+}, \mathrm{e}_{\mathrm{CB}}^{-}\right)$ and hydroxyl radicals. In order to evaluate these two paths, experiments were performed by adding different amounts of ethanol to the solution. Alcohols such as ethanol are commonly used to quench hydroxyl radicals [21]. The rate constant of reaction between hydroxyl radicals and ethanol is $1.9 \times 10^{9} \mathrm{M}^{-1} \mathrm{~s}^{-1}$, which is significantly high [21]. As it is observed from Figure 7, adding small amounts of ethanol, up to $0.3 \%(\mathrm{v} / \mathrm{v})$, decreases the degradation efficiency of AY36. On the other hand, adding extra amount of ethanol leads to a mild increase in the process efficiency due to the formation of ethoxy radicals $\left(\mathrm{C}_{2} \mathrm{H}_{5} \mathrm{O}^{\circ}\right)$ from direct photocatalytic oxidation of ethanol; meanwhile, the ethanol molecules can produce hydroxyl radicals in direct photolysis with respect to the level of $\mathrm{C}-\mathrm{O}$ energy bond [21].

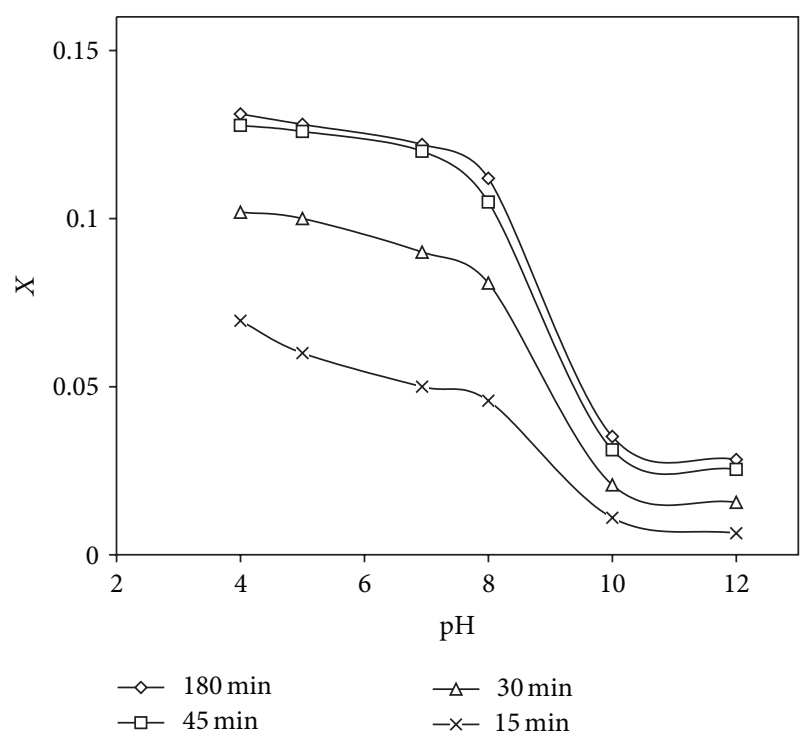

Figure 6: Darkness adsorption of AY36 on the catalyst surface at different $\mathrm{pH}$ values, $[\mathrm{AY} 36]_{0}=50 \mathrm{mg} \mathrm{L}^{-1}$ and $[\mathrm{ZnO}]=1 \mathrm{~g} \mathrm{~L}^{-1}$.

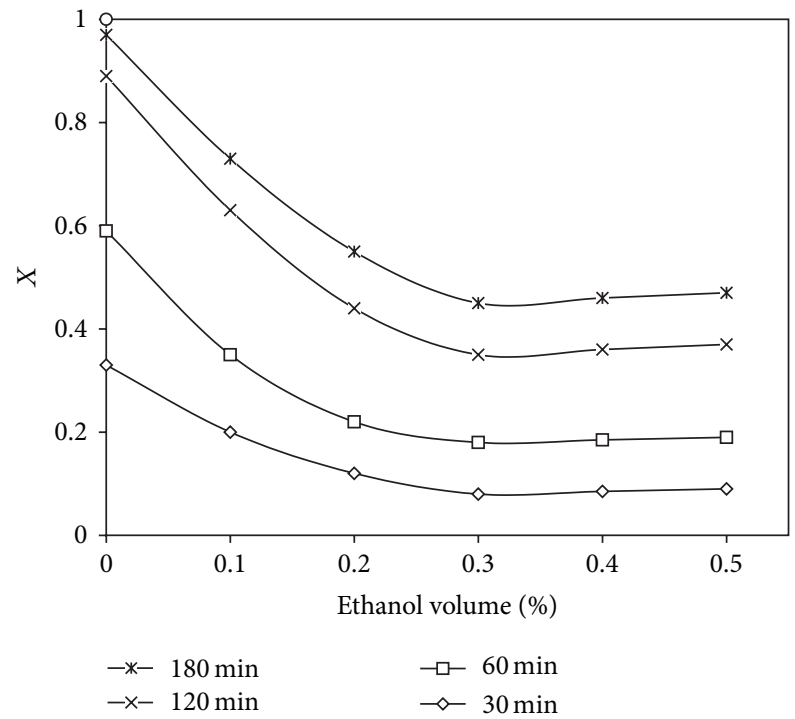

FIGURE 7: Inhibitory effect of ethanol on photocatalytic degradation efficiency of AY36, $[\mathrm{AY} 36]_{\mathrm{o}}=50 \mathrm{mg} \mathrm{L}^{-1},[\mathrm{ZnO}]=1 \mathrm{~g} \mathrm{~L}^{-1}$, and $\mathrm{pH}=$ 6.93 .

From data given in Figure 7, the contribution of hydroxyl radicals and electron holes in the photocatalytic degradation process at different times is determined and compared in Figure 8. As it can be seen in this figure, hydroxyl radicals play a major role in photocatalytic degradation of AY36 in all the times. Another species involved which does not react with alcohols is most probably the positive holes $\left(\mathrm{h}_{\mathrm{VB}}^{+}\right)$formed on the irradiated photocatalyst, which react with the adsorbed dye molecules.

3.6. Electrical Energy Efficiency. The effect of light intensity on the photoconversion efficiency is an interesting approach 


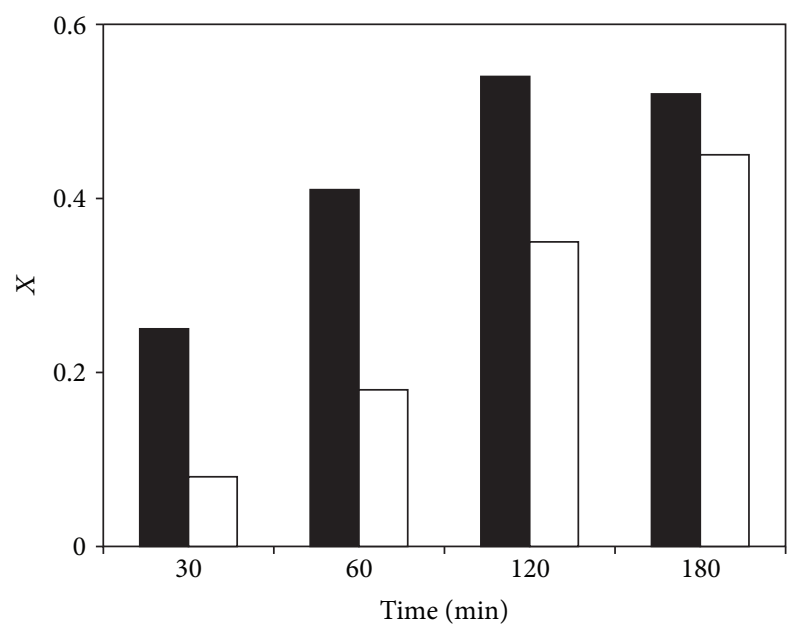

- OH radical portion based

$\square$ Electron-hole portion based

FIgURE 8: Contribution of active species in AY36 conversion at different times in photocatalysis process; $[\mathrm{AY} 36]_{\mathrm{o}}=50 \mathrm{mg} \mathrm{L}^{-1}$, $[\mathrm{ZnO}]=1 \mathrm{~g} \mathrm{~L}^{-1}$, and $\mathrm{pH}=6.93$.

to simulate a real utilization condition. Recently, the determination of the electrical energy by order of magnitude $E_{E O}$ was recommended by the IUPAC as a figure of merit of the photocatalytic system. $E_{E O}$ is defined as the number of $\mathrm{kW} / \mathrm{h}$ required to remove the concentration of pollutant by one order of magnitude $(90 \%)$ in $1 \mathrm{~m}^{3}$ of contaminated water. Equation (8) can be used to calculate the UV dose; also, the value of $E_{E O}$ was obtained using (9) from the energy dose $\left(\mathrm{kWh} \mathrm{m}^{-3}\right)$ versus inverse of the slope of a plot of $\log \left(C_{o} / C\right)$ $[16,22]$ :

$$
\begin{gathered}
\mathrm{UV} \text { dose }=\frac{\text { lamp power }(\mathrm{kW}) \times \text { time }(\mathrm{h})}{\text { treated volume }(\mathrm{L}) \times 10^{-3}}, \\
E_{E O}=\frac{\mathrm{UV} \mathrm{dose}}{\log \left(C_{\mathrm{o}} / C\right)},
\end{gathered}
$$

where $C_{\mathrm{o}}$ and $C$ are the initial and final AY36 concentrations. Since, at natural $\mathrm{pH}$ of 6.93 and catalyst concentration of $1 \mathrm{~g} \mathrm{~L}^{-1}$, the required time for $90 \%$ decolorization of the one liter of solution containing $50 \mathrm{mg} \mathrm{L}^{-1}$ of AY36 was $122 \mathrm{~min}$, the $E_{E O}$ value has been determined as $36.6 \mathrm{kWh} \mathrm{m}^{-3}$. However, at $\mathrm{pH}$ of 8 , the required time for $90 \%$ decolorization of the one liter of solution containing $50 \mathrm{mg} \mathrm{L}^{-1}$ of AY36 in presence of $1 \mathrm{~g} \mathrm{~L}^{-1}$ of catalyst was $93 \mathrm{~min}$; thus, the $E_{E O}$ value has been determined as $27.9 \mathrm{kWh} \mathrm{m}^{-3}$.

\section{Conclusions}

Effective photocatalytic degradation of the monoazo dye Acid Yellow 36 (AY36) is available in $\mathrm{ZnO}$ catalyst suspended aqueous solutions and during short times of UV irradiation when compared with only photo-degradation process. We learned that optimal amount of photocatalyst was $1 \mathrm{~g} \mathrm{~L}^{-1}$, with dye concentration of $50 \mathrm{mg} \mathrm{L}^{-1}$. The most efficient $\mathrm{pH}$ for the photocatalytic decomposition of AY36 was 8, and zinc oxide cannot be used in acidic solution $(\mathrm{pH} \leq 4)$ as a photocatalyst; however, the maximum amount of dark surface adsorption was observed at $\mathrm{pH}$ of 4 . As our results showed that ethanol inhibited the photodegradation of dye, we concluded from the inhibitory effect of ethanol that hydroxyl radicals play a major role in photocatalytic degradation of AY36 in all the times. The complete removal of color, after selection of optimal concentration of catalyst $\left(1 \mathrm{~g} \mathrm{~L}^{-1}\right)$, could be achieved in a relatively short time of about $120 \mathrm{~min}$ at $\mathrm{pH}$ of 8 .

\section{References}

[1] E. Guivarch, S. Trevin, C. Lahitte, and M. A. Oturan, "Degradation of azo dyes in water by Electro-Fenton process," Environmental Chemistry Letters, vol. 1, no. 1, pp. 38-44, 2003.

[2] M. Sleiman, D. Vildozo, C. Ferronato, and J. M. Chovelon, "Photocatalytic degradation of azo dye metanil yellow: optimization and kinetic modeling using a chemometric approach," Applied Catalysis B, vol. 77, no. 1-2, pp. 1-11, 2007.

[3] Y. H. Lee and S. G. Pavlostathis, "Decolorization and toxicity of reactive anthraquinone textile dyes under methanogenic conditions," Water Research, vol. 38, no. 7, pp. 1838-1852, 2004.

[4] I. K. Konstantinou and T. A. Albanis, " $\mathrm{TiO}_{2}$-assisted photocatalytic degradation of azo dyes in aqueous solution: kinetic and mechanistic investigations: a review," Applied Catalysis B, vol. 49, no. 1, pp. 1-14, 2004.

[5] J. Grzechulska and A. W. Morawski, "Photocatalytic decomposition of azo-dye acid black 1 in water over modified titanium dioxide," Applied Catalysis B, vol. 36, no. 1, pp. 45-51, 2002.

[6] C. Galindo, P. Jacques, and A. Kalt, "Photooxidation of the phenylazonaphthol $\mathrm{AO} 20$ on $\mathrm{TiO}_{2}$ : kinetic and mechanistic investigations," Chemosphere, vol. 45, no. 6-7, pp. 997-1005, 2001.

[7] J. Saien and S. Khezrianjoo, "Degradation of the fungicide carbendazim in aqueous solutions with $\mathrm{UV} / \mathrm{TiO}_{2}$ process: optimization, kinetics and toxicity studies," Journal of Hazardous Materials, vol. 157, no. 2-3, pp. 269-276, 2008.

[8] M. R. Hoffmann, S. T. Martin, W. Choi, and D. W. Bahnemannt, "Environmental applications of semiconductor photocatalysis," Chemical Reviews, vol. 95, no. 1, pp. 69-96, 1995.

[9] B. Dindar and S. Içli, "Unusual photoreactivity of zinc oxide irradiated by concentrated sunlight," Journal of Photochemistry and Photobiology A, vol. 140, no. 3, pp. 263-268, 2001.

[10] M. C. Yeber, J. Rodríguez, J. Freer, J. Baeza, N. Durán, and H. D. Mansilla, "Advanced oxidation of a pulp mill bleaching wastewater," Chemosphere, vol. 39, no. 10, pp. 1679-1688, 1999.

[11] A. A. Khodja, T. Sehili, J. F. Pilichowski, and P. Boule, "Photocatalytic degradation of 2-phenylphenol on $\mathrm{TiO}_{2}$ and $\mathrm{ZnO}$ in aqueous suspensions," Journal of Photochemistry and Photobiology A, vol. 141, no. 2-3, pp. 231-239, 2001.

[12] B. Krishnakumar and M. Swaminathan, "Influence of operational parameters on photocatalytic degradation of a genotoxic azo dye Acid Violet 7 in aqueous $\mathrm{ZnO}$ suspensions," Spectrochimica Acta A, vol. 81, no. 1, pp. 739-744, 2011.

[13] M. A. Behnajady, N. Modirshahla, and R. Hamzavi, "Kinetic study on photocatalytic degradation of C.I. Acid Yellow 23 by ZnO photocatalyst," Journal of Hazardous Materials, vol. 133, no. 1-3, pp. 226-232, 2006.

[14] M. Sylwia, A. W. Morawski, M. Toyoda, and T. Tsumura, "Effect of process parameters on photodegradation of Acid Yellow 
36 in a hybrid photocatalysis-membrane distillation system," Chemical Engineering Journal, vol. 150, no. 1, pp. 152-159, 2009.

[15] Y. Pratibha and R. C. Meena, "Methylene blue immobilized resin dowex-11 as photo catalyst for UV light irradiation assisted degradation of Acid Yellow 36," International Journal of Chemistry and Applications, vol. 3, no. 1, pp. 11-18, 2011.

[16] N. Daneshvar, A. Aleboyeh, and A. R. Khataee, "The evaluation of electrical energy per order $\left(E_{E o}\right)$ for photooxidative decolorization of four textile dye solutions by the kinetic model," Chemosphere, vol. 59, no. 6, pp. 761-767, 2005.

[17] H. H. Ou, S. L. Lo, and S. H. Wu, "Exploring the interparticle electron transfer process in the photocatalytic oxidation of 4chlorophenol," Journal of Hazardous Materials B, vol. 137, no. 3, pp. 1362-1370, 2006.

[18] S. K. Kansal, M. Singh, and D. Sud, "Studies on photodegradation of two commercial dyes in aqueous phase using different photocatalysts," Journal of Hazardous Materials, vol. 141, no. 3, pp. 581-590, 2007.

[19] C. Zhu, L. Wang, L. Kong et al., "Photocatalytic degradation of AZO dyes by supported $\mathrm{TiO}_{2}+\mathrm{UV}$ in aqueous solution," Chemosphere, vol. 41, no. 3, pp. 303-309, 2000.

[20] S. Anandan, A. Vinu, N. Venkatachalam, B. Arabindoo, and V. Murugesan, "Photocatalytic activity of $\mathrm{ZnO}$ impregnated $\mathrm{H} \beta$ and mechanical mix of $\mathrm{ZnO} / \mathrm{H} \beta$ in the degradation of monocrotophos in aqueous solution," Journal of Molecular Catalysis A, vol. 256, no. 1-2, pp. 312-320, 2006.

[21] J. Saien, H. Delavari, and A. R. Solymani, "Sono-assisted photocatalytic degradation of styrene-acrylic acid copolymer in aqueous media with nano titania particles and kinetic studies," Journal of Hazardous Materials, vol. 177, no. 1-3, pp. 1031-1038, 2010.

[22] N. Daneshvar, D. Salari, A. Niaei, M. H. Rasoulifard, and A. R. Khataee, "Immobilization of $\mathrm{TiO}_{2}$ nanopowder on glass beads for the photocatalytic decolorization of an azo dye C.I. Direct Red 23," Journal of Environmental Science and Health A, vol. 40, no. 8, pp. 1605-1617, 2005. 

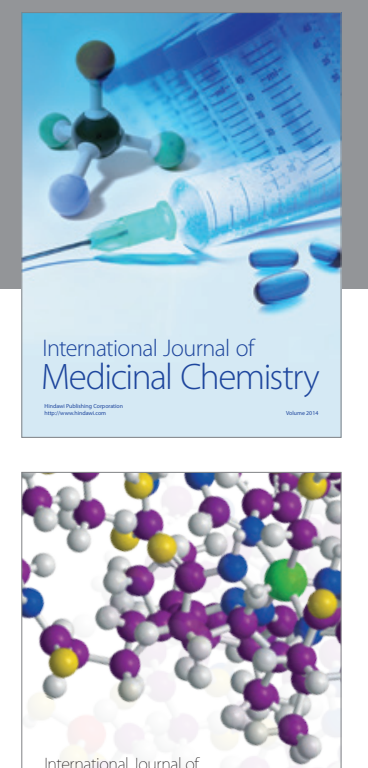

\section{Carbohydrate} Chemistry

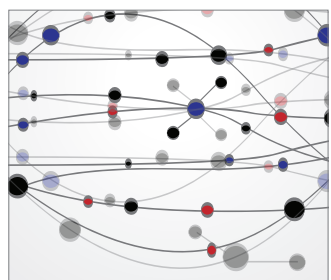

The Scientific World Journal
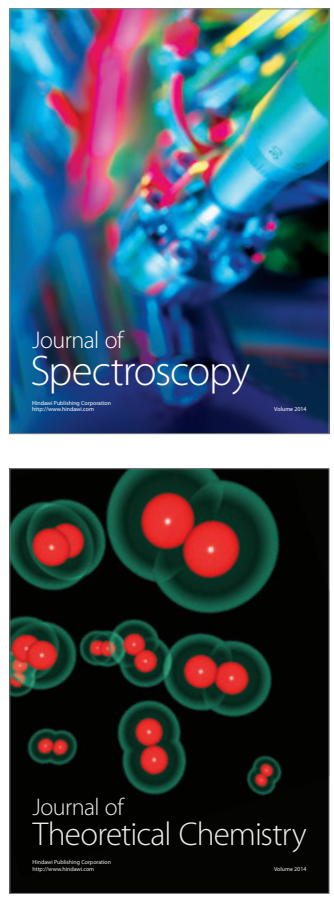
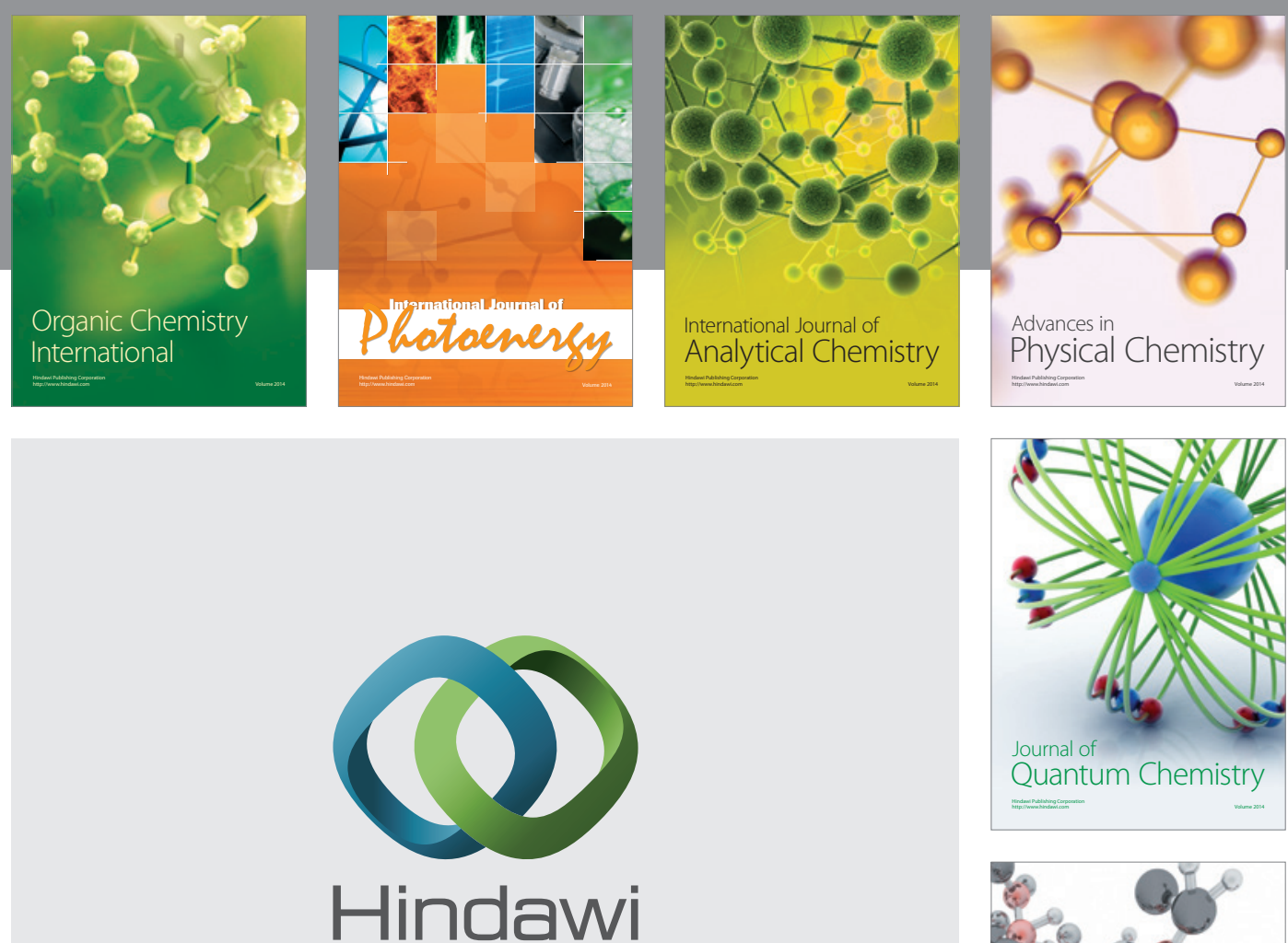

Submit your manuscripts at

http://www.hindawi.com

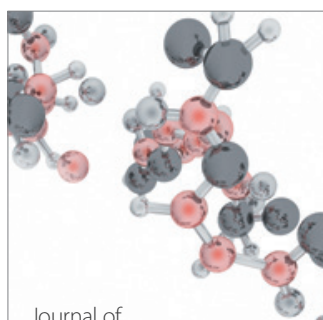

Analytical Methods

in Chemistry

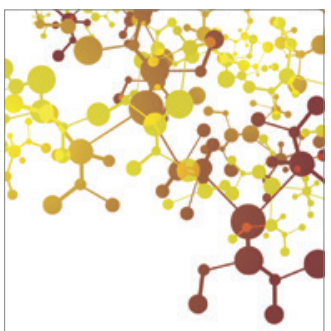

Journal of

Applied Chemistry

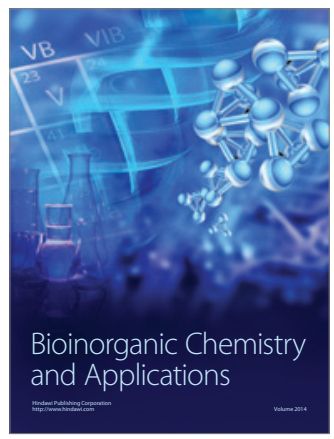

Inorganic Chemistry
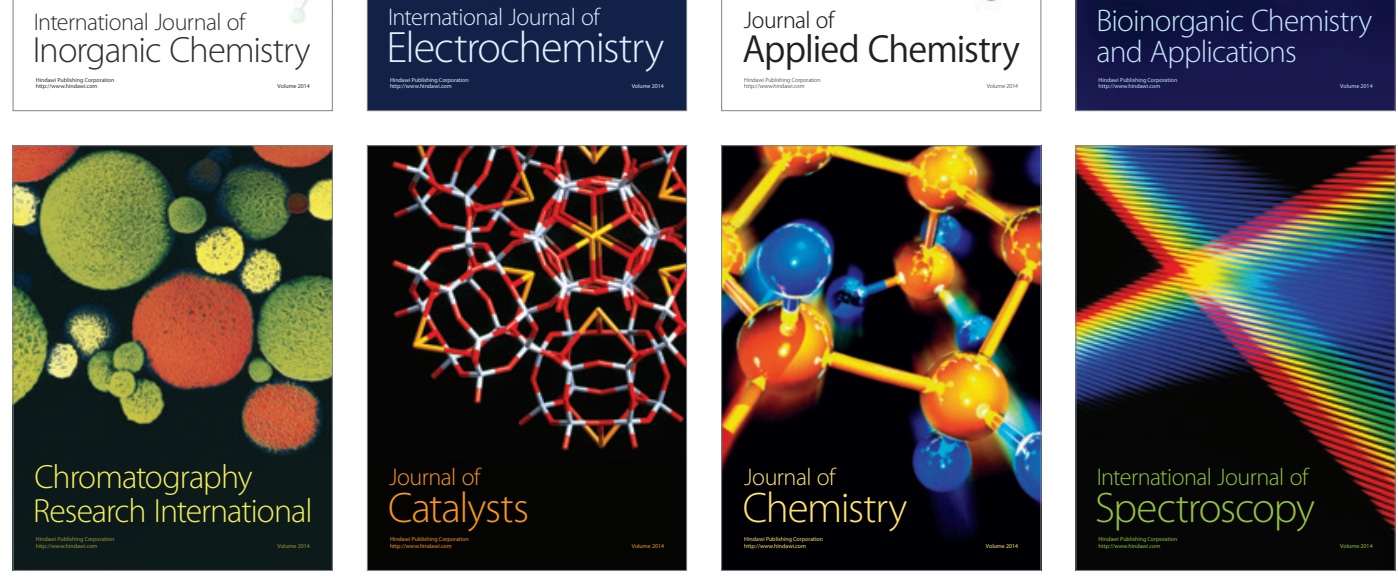